which stays commendably close to the practical realities of everyday practice. Weighing in at $2 \mathrm{lb} 10 \mathrm{oz}$ and with 90 pages of references it may initially appear disconcertingly heavyweight but is none the less lucidly written and carefully designed to enhance its readability and usefulness. Propositions, definitions and models are all clearly described, the evidence in support of each is critically evaluated and reviews are helpfully punctuated by succinct summaries and conclusions - including the limitations of the evidence itself.

It centres on the needs of people with severe mental illness in ten basic life domains including work, housing, education and family. Alongside well-shaped reviews of familiar topics, such as case management and medication, are challenging areas including managing aggression and people with dual diagnosis. These are usefully extended into emerging areas of collaborative practice such as self-management and peer-provided services.

They have sought to produce an evidence-based text where the research speaks for itself, unembroidered by speculation or opinion. But it is never really possible to serve up theory-free facts or value-free observations and they appear to show a little of their otherwise invisible editorial hand in dismissively lumping psychoanalytic considerations with mesmerism and phrenology as historical artefacts that 'have no utility in understanding disabilities and yielding no benefits in addressing the needs of people with serious mental illnesses'.

This is probably the best account of the evidence base for contemporary rehabilitation practice to date and a commendable starting place for further study or research. In building their book upon the twin foundations of empowerment and recovery they have produced a text which is highly complementary to Enabling Recovery (a title I co-edited for Gaskell in 2007) and a welcome contribution to the redevelopment of rehabilitation in the context of recovery-oriented practice. But I do hope that their neologistic identification of consumers who also provide services as 'prosumers' does not survive the voyage across the Atlantic.

Glenn Roberts Wonford House Hospital, Dryden Road, Exeter EX2 5AF, UK. Email: glennroberts@doctors.org.uk

doi: 10.1192/bjp.bp.108.049775

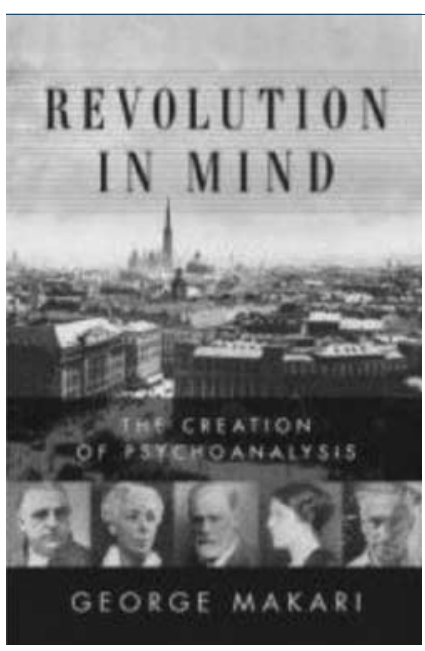

\section{Revolution in Mind: The Creation of Psychoanalysis}

By George Makari. Duckworth Press. 2008.

624pp. $£ 25.00$ (hb).

ISBN: 9780715637593

Is there room for yet another book on the history and development of psychoanalysis? I was doubtful at first, but my initial scepticism was overturned after reading this book. George Makari sets a very effective boundary around his vast subject: he tries to cover not only the history of psychoanalysis, but the history of ideas throughout the formative period of modern Western thought, from about 1870 to 1940, with a brief epilogue about the post-War years.

Makari is of his time: he reflects a current preoccupation in the US of going back to the 'founding fathers'. He describes Freud's ability to generate original thought from a synthesis of the important ideas of the 19th century. He also shows the ruthless, Machiavellian side to Freud's character in maintaining control of psychoanalysis as a distinct body of ideas. In modern terms, Freud was managing a brand name and fighting to maintain ownership. However, after this initial period, Freud shows flexibility in superseding his own theories with new ideas, keeping psychoanalysis from being merely a dogmatic school of acolytes.

Admittedly, the book covers familiar ground but it does that through some beautifully researched material on the political development of psychoanalysis. This is one of the clearest accounts I have read of this period. Makari's ability to situate the internecine struggles of psychoanalysis within broader history of Europe made me look at his sources to check the accuracy of the connections. I did not find a single mistake and the excellent endnotes and index made the task simple. Makari adopts the modern style of having extensive endnotes and index (nearly a fifth of the whole book in all) but with no intrusive references or footnotes in the text to distract the reader. He writes in a style that makes his book equally absorbing as a holiday book and a textbook and it will attract non-clinicians as much as practitioners.

Inevitably, some sections could be expanded. For instance, the account of the crucial controversial discussions was succinct but a little too brief, whereas the development of ego psychology in North America is covered in detail. These individual preferences are unavoidable in a book of this type, but overall I recommend it to anyone who wants to understand Freud in his historic context. It is salutary that current arguments about technique and theory have their roots in these arguments from over a century ago.

Frank R. Margison Gaskell Psychotherapy Centre, Swinton Grove, Mancheste M13 OEU, UK. Email: frank.margison@mhsc.nhs.uk

doi: 10.1192/bjp.bp.108.050849

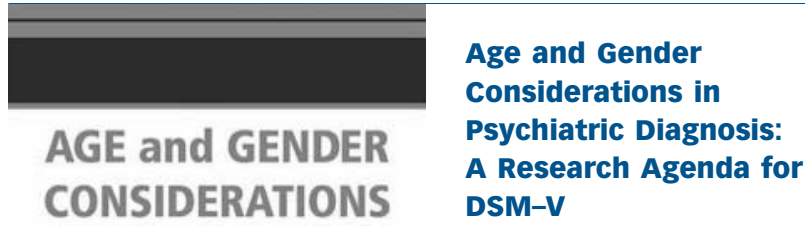

in Psychiatric Diagnosis

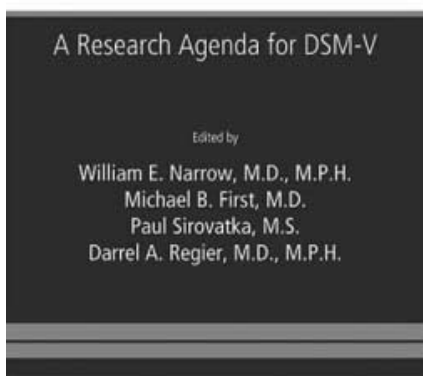

Edited by William E. Narrow, Michael B. First, Paul Sirovatka \& Darrel A. Regier. American Psychiatric Association. 2007. 382pp. US\$55.00 (pb). ISBN: 9780890422953

The fifth edition of the Diagnostic and Statistical Manual of Mental Disorders (DSM-V) is due to be completed in 2011 and this volume, while not part of the official DSM revision process, is intended as a source document for the DSM-V Task Force as well as to provide guidance and recommendations for the longer-term 